\title{
Музыкальное образование
}

\section{Елена Алкон}

\section{РАЗВИТИЕ ВНУТРЕННЕГО САУХА НА МАТЕРИАЛЕ ЭСТРАДНОЙ МУЗЫКИ}

Развитый музыкальный слух необходим каждому профессиональному музыканту, и сушествует много способов его совершенствования. Выдаюшийся психолог Б.М. Теплов предлагал относить к основным музыкальным способностям следуюшие: ладовое чувство (перцептивный компонент), способность $\kappa$ слуховому представлению (репродуктивный компонент) и музыкальноритмическое чувство (двигательный компонент). Обратим внимание, что ладовое чувство Теплов определяет, в отличие от «школьного», упрошенного представления о ладовом слухе, как различение тяготений неустойчивых звуков в устойчивые, через феномен эмоџиональности. Психолог характеризует ладовое чувство как способность «эмоционально различать ладовые функции звуков мелодии», или, что то же, «чувствовать эмоциональную выразительность звуковысотного движения» [11, с. 238]. Вторая способность заключается в умении «произвольно пользоваться слуховыми представлениями» [11, с. 238] как в реальной музыкальной практике, так и без какихлибо видимых проявлений этой работы. Наконед, третья из основных музыкальных способностей - это «способность активно (двигательно) переживать музыку, чувствовать эмоциональную выразительность музыкального ритма и точно воспроизводить последний» $[11$, с. 238].

В связи с темой настоящей статьи важно подчеркнуть, что слабость слуховых представлений, согласно исследованиям Теплова, наиболее часто тормозит развитие остальных музыкальных способностей [11, с. 254]. Из этого следует первоочередная задача развития слуховых представлений, которые иначе называют внутренним слухом. Внутренний слух определяется как «способность представлять музыку в сознании, внутренне слышать и переживать, не исполняя и реально не слушая ее, а узнавая и воспроизводя музыку по памяти, в проџессе чтения нот или творческого созидания» $[8$, с. 5]. Эта музыкальная способность опирается на слуховое восприятие (слух внешний), связана с музыкальной памятью, имеет сложную структуру и, что особенно важно, чрезвычайно трудно поддается развитию [8, с. 25-26]. К формам внутреннего слуха относятся внутреннее слышание и внутреннее пение. На качество внутреннего слуха воздействуют три фактора: следовые звуко- 
высотные рефлексы (условные и безусловные), от которых зависит содержание, форма и качество внутренних слуховых представлений; представление координации элементов музыкальной ткани и объем представлений, формируюшийся проџессами запоминания и сохранения информаџии [9, с. 22-23].

В настоящее время одним из наиболее эффективных способов развития внутреннего слуха могут стать самодиктанты на материале эстрадной музыки. Обратим внимание на то, что это вид самостоятельной работы студента, осушествляемой под руководством преподавателя. Вообще говоря, запись хорошо знакомых мелодий - не только полезное, но и довольно увлекательное занятие. Задание это можно выполнять в курсе сольфеджио - предмета, наџеленного на всестороннее развитие музыкального слуха и музыкального мышления. Однако ни для кого не секрет, что к сольфеджио значительная часть студентов особой любви не испытывает. Материал эстрадной, популярной музыки может сделать эту дисџиплину более интересной и привлекательной. Популярные эстрадные песни, песни из кинофильмов, то есть та музыка, которая нравится студентам, уже закреплена в памяти. Причем, эмоциональная привлекательность лишь облегчает запоминание и, таким образом, делает эту музыку еше более удобным материалом для самодиктанта. Несмотря на то, что ноты многих, хотя и далеко не всех, эстрадных песен сегодня более доступны благодаря Интернету, акустические тексты, то есть устные исполнительские версии чаше всего имеют отличия от нотных версий, записанных композитором. Давая задание, студентов следует ориентировать на запись именно устной исполнительской версии, рекомендуя то или иное конкретное исполнение.

Проџесс записи самодиктанта очень близок творческому проџессусочинению: хорошо усвоенный, в хорошем смысле «присвоенный», закрепленный в памяти музыкальный материал становится близким, своим; записывающий его в какой-то момент начинает чувствовать себя автором, композитором, его придумавшим: в голове уже все есть - остается только записать, перенести на бумагу, сделать невидимое видимым. Но ведь то же самое делает и автор, когда сочиняет музыку. «Расшифровка» мелодии (если воспользоваться терминологией фольклористов), ее «перевод» из устного / ментального в письменный / визуальный вид нередко вызывает чувство, сходное с удивлением, когда обнаруживается некое несоответствие слухового представления (того, как песня «выглядит в голове») ее «рисунку» в пятилинейной нотаџии. Заметим, что своеобразие письменной записи музыки как способа кодирования становится еше более очевидным, если в самом обшем виде познакомить студентов (например, в курсе теории музыки) с другими нотаџиями - невменной, или разнообразными китайскими и корейскими, наиболее изученными в отечественном музыкознании [6; 7]. Подобные сопоставления позволяют взглянуть иначе на привычный способ записи в пяти- 
линейной нотаџии, оџенить еще раз ее возможности и ограничения, обратить внимание как на то, что нотами записать можно, так и на то, что ей неподвластно. Через самостоятельную запись песни, крепко зафиксированной в памяти, можно ближе подойти к ее пониманию, отыскать ее «изюминку», загадку, понять почему же именно она стала такой популярной и любимой, в чем ее художественная џенность.

Что представляет собой самодиктант как форма работы? Сегодня она, видимо, не слишком известна, если судить по тому, что студенты зачастую не понимают, о чем идет речь, когда на занятиях заходит разгово об этом задании. Тем не менее, еше недавно такая форма работы была достаточно популярна. Условия для ее применения в чем-то были более, а в чем-то менее благоприятны нежели сегодня, но в любом случае они были другими. С появлением Интернета самодиктант может стать одной из важнейших форм развития не только музыкального слуха, но и личности музыканта, причем не только студента, но и преподавателя. Использование этой формы работы предполагает постоянный поиск нового материала и методов работы с ним. $\mathrm{O}$ необходимости меняться самому педагогу сегодня говорят как о наболевшей проблеме. Сила инерџии в преподавании сольфеджио достаточно велика, и вопрос отбора музыкального материала, качественного, интересного для обучающихся и способствующего развитию личности, сегодня приобрел особую остроту [3].
Самодиктант, по нашим наблюдениям, является одним из самых эффективных и полезных упражнений для развития внутреннего слуха, а значит, и всего комплекса музыкальных способностей, включая творческие навыки. Особенно близким материал эстрадной музыки является, конечно, для студентов, обучающихся эстрадно-джазовому пению. Немало среди талантливой молодежи тех, кто не только обладает очень хорошими вокальными данными, музыкальностью, но уже сочиняет музыку, что вполне естественно: одаренный исполнитель всегда обладает также и композиторским даром [5, с. 291309]. Однако, далеко не все вокалистыэстрадники, поступающие в вуз, обладают хорошим базовым образованием в объеме музыкальной школы и училища. Для тех, кто стремится как можно быстрее наверстать упущенное, самодиктант может стать одной из наиболее полезных и эффективных форм работы.

Задавая мелодии для самодиктантов, следует отбирать их, выстраивая материал от простого к сложному, наџеливая учащихся на освоение различных интонаџионных оборотов, ладов, хроматизмов, отклонений и модуляџий, типов тональных соотношений. Желательно, чтобы песни отличались разнообразием стилей и высокими художественными достоинствами. В этом отношении современная әстрада уступает песням прошлых лет по качеству поэтических текстов, по содержательности, по развитости мелодии, гармонии, формы. Поэтому освоение мелодий XX века, которые закрепились в качестве класси- 
ки жанра и вернулись на эстраду либо пока еще незаслуженно забыты, сущест венно расширит кругозор, обогатит стилевой опыт студента и будет способствовать преодолению слуховых инерџий. Иногда сложность и красота эстрадных песен второй половины XX века воистину ошеломляет нынешних студентов. Сильное впечатление произвело на них, например, знакомство с альбомом Д. Тухманова «По волне моей памяти»: настолько непривычными для их слуха оказались и поэтические тексты - высокая любовная лирика Шарля Бодлера, Анны Ахматовой, Поля Верлена и других поэтов; и музыка - сложные и выразительные по форме, красивые, оригинальные мелодии.

Развитие музыкального слуха, отмечает Ю.Н. Бычков, включает формирование таких свойств как активность и иниџиативность. «Слух должен “схватывать” явления, создавать, интонировать мелодические построения, которые раньше не были даны ему в опыте. Одним из условиї этого является способность разложить освоенный звуковой материал, выделить из него различные әлементы» [4, с. 31]. Таким образом, самодиктанты на материале качественной эстрадной музыки могут не только развивать интонаџионны мелодический, гармонический, архитектонический слух, музыкальную память, чувство ритма [Подробнее см.: 5, с. 60-245], но, что может быть еще более важно, способствовать формированию музыкального вкуса. Кроме того, они развивают рефлексию, отличающую профессионального музыканта от

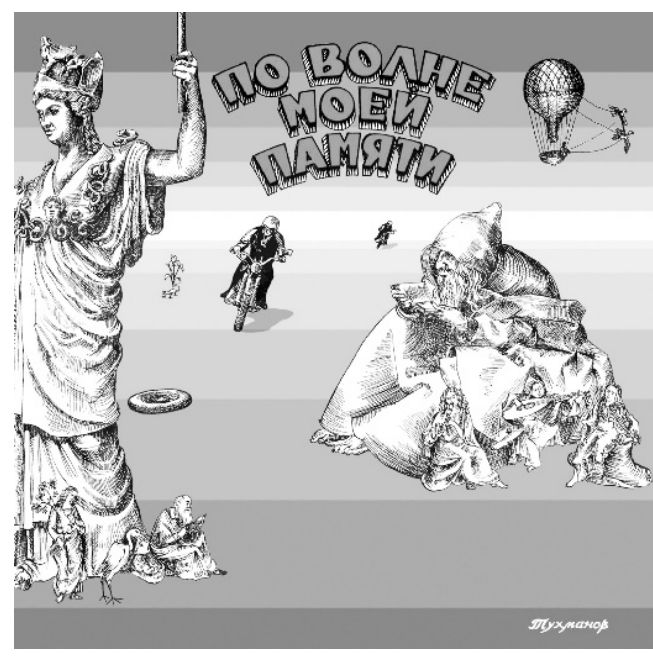

Сильное впечатление произвело на студентов знакомство с альбомом Д. Тухманова «По волне моей памяти»

любителя музыки. Эстрадно-джазовое пение в большей степени, чем другие музыкальные специальности, ориентировано на устный тип деятельности, а также на иные формы «письменности» (аудио, видео), поэтому перевод слуховых представлений в письменные знаки и анализ написанного создает необходимые, спеџиальные условия для формирования профессионализма и развития музыкальных способностей. Важно и то, что популярные песни стилистически коррелируют с нормами классической и романтической мелодии и гармонии и дают дополнительный материал для освоения и закрепления в курсе сольфеджио того, что студенты изучают в курсе гармонии.

Итак, что представляет собой музыкальный самодиктант как вид самостоятельной работы студента? Самодиктант - это запись по памяти «из- 
вестной мелодии, ранее изученной или услышанной (песни с текстом, инструментальной мелодии), или воспроизведение запомнившейся гармонической последовательности» [10, с. 36]. Самодиктант считается особенно полезным в домашней работе, но можно применять его также и при работе в классе. Появление Интернета создает весьма благоприятные условия для работы над самодиктантами. Так, если раньше, давая задание записать по памяти ту или иную песню, нередко приходилось слышать от студента, что она ему неизвестна, и потому выполнить задание он не может, то сегодня этой проблемы больше не существует. Практически любую песню можно найти на самом крупном сайте www.youtube.com. Существуют и специализированные Интернет-ресурсы, такие, например, как www.sovmusic.ru - собрание исполнений отечественных песен советского времени.

Следует отметить, что самодиктант как вид самостоятельной работы в большей степени соответствует современной парадигме образования, в которой огромная роль отводится самообразованию под руководством преподавателя. Подобная конџепџия образования приходит на смену парадигме проиесса обучения, где главная роль принадлежала педагогу. В данном случае задача преподавателя заключается в том, чтобы отобрать материал, выстроить его, рекомендовать то или иное исполнение, а затем проверить выполнение задания. Можно идти навстречу желаниям студентов, если им уже «по силам» та песня, с которой хочется поработать.
Комплексное, глубокое изучение музыкального материала песни только начинается с ее записи нотами.

Несмотря на очевидно благотворную роль Интернета в работе над самодиктантом, есть и минусы, связанные с появлением всемирной паутины. Сегодня в Сети можно найти и нотные записи песен, и аккорды к ним, и студенты идут на подобные уловки, а также обращают ся к сокурсникам за готовыми текстами, записанными более ответственными и добросовестными учащимися. Ничего не поделаешь: в таких случаях речь, конечно, уже не идет о развитии внутреннего слуха, и преподавателю остается смириться с тем, что имеет место работа менее самостоятельная. Но даже в этом случае проработка и заучивание песни наизусть по нотам, собственное исполнение аккомпанемента как необходимое условие контроля над выполнением задания тоже приносит немалую пользу, хотя, конечно, и меньшую.

Желательно брать для самодиктантов те мелодии песен, которые студент уже хорошо знает и может спеть. Можно предложить следуюшую последовательность самостоятельной работы над самодиктантом (как правило, работа выполняется дома, но иногда она может быть выполнена и в классе под наблюдением преподавателя):

1) обязательно послушать песню целиком, может быть, несколько раз (даже если кажется, что и мелодия, и аккомпанемент хорошо известны), не останавливая звучание и внимательно вслушиваясь. Это необходимо сделать для того, чтобы сверить «собствен- 
ную версию» с оригинальной. Нередки случаи, когда точность представления о звучании кажущаяся, и в памяти хранится несколько упрошенный вариант мелодии и аккомпанемента;

2) записать мелодию нотами без повторных прослушиваний и без пропевания вслух; ритм удобнее записывать в инструментальной группировке;

3) проверить правильность записи, проиграв ее на фортепиано;

4) разметить цезуры, разделить мелодию на крупные сегменты (фразы, предложения), выделить (обвести овалом) наиболее характерные именно для этой мелодии обороты, определяюшие ее лиџо: интонаџии, ладовые архетипы (трихордовые структуры), наиболее выразительные мотивы, движение по звукам аккордов;

5) наметить моменты смены гармонии, а по звукам мелодии возможные аккорды аккомпанемента; при затруднении следует определить, каким является метрически опорный звук мелодии - аккордовым или неаккордовым; если он аккордовый, то следует определить каким тоном (примой, териией, квинтой, септимой или ноной) может быть этот звук мелодии в аккорде (определять следует внутренним слухом, без инструмента);

6) записать подобранные к мелодии аккорды, желательно двумя стандартами: сверху над мелодией - эстрадноджазовым (например, Cm6), внизу классическим, функџиональным (T, S, D, VI и т.п.), с указанием квадратными скобками над текстом всех промежуточ- ных тональностей, если таковые имеются. Проверить гармонию за фортепиано.

Контроль за выполнением этих заданий для преподавателя - дело нелегкое. Но, в данном случае, џель все-таки оправдывает затраты времени и сил. Итак, можно предложить следующй порядок «приема - сдачи» работы:

1) проверка записи нотного текста: преподавателю следует проверить мелодию, ее соответствие тому, как поет ее сам студент (можно попросить спеть отдельно, со словами, сомнительные фразы или мотивы, чтобы сверить с предлагаемой нотной записью). Нередко тот вариант, который студент считает правильным, является упрощенным или искаженным. Чтобы студент исправил неверные фрагменты, преподавателю следует самому точно пропеть нужную фразу или мотив;

2) сольфеджирование мелодии наизусть (без аккомпанемента): проверяется соответствие пения тексту, записанному нотами;

3) проверка подбора аккомпанемента: исполнение песни со словами под собственный аккомпанемент, желательно, в соответствующем темпе, ритме, фактуре.

Для развития внутреннего слуха полезными могут быть также эвристические, поисковые задания, для выполнения которых необходимо перебрать в уме, внутренним слухом значительное количество мелодий, чтобы найти ответ. Например, дается задание найти внутренним слухом и записать нотами песни, в которых есть выразительные интонаџии восходящей или нисходящей 
чистой кварты, восходяшей уменьшенной кварты, нисходящей и восходящей малой сексты, нисходящее движение по звукам $\mathrm{VI}_{3}^{5}$, восходящее движение по звукам $\mathrm{T}^{6}{ }_{4}$, нисходящее движение по звукам $\mathrm{II}_{7}, \mathrm{II}^{6}{ }_{5}$ и т.п. Освоенный материал можно использовать как фундамент для дальнейшей работы. Для освоения всех тональностей - устно транспонировать самодиктанты, петь их в разных тональностях. Для развития творческих способностей можно давать задания сочинять варианты на песню, записанную как самодиктант, придумывать собственные мелодии на характерный гармонический оборот из песни, на определенный тип структуры (периодичность, суммирование, дробление и др.), на заданный или на собственный стихотворный текст.

Подводя итоги, вспомним о том, что функция преподавателя состоит в том, чтобы предложить студенту определенный музыкальный материал, осваивая который, он вырабатывает необходимые навыки, обогащает собственную психику, проникает в присущие материалу отношения [4, с. 14] и формируется как личность.

В заключение приведем примерный список вокальных произведений для самодиктантов с во многом условным распределением их по уровням сложности (первым в списке указан автор музыки, вторым - автор слов; там, где дано имя одного автора, ему / ей принадлежит авторство и музыки, и слов).

Первый уровень:

1. «Подмосковные вечера» (В. Соловьев-Седой, М. Матусовский);
2. «Улыбка» (из м/ф «Крошка Енот») (В. Шаинский, М. Пляџковскиї);

3. «Silent Night» (J. Mohr, F.X. Gruber);

4. «Непогода» (из к/ф «Мәри Поппинс, до свидания!») (М. Дунаевский, Н. Олев);

5. «Песенка о медведях» (из к/ф «Кавказская пленниџа») (А. Заџепин, ᄉ. Дербенев);

6. «Let it be» (из репертуара «The Beatles») (P. McCartney, J. Lennon);

7. «Маленький принџ» (М. Таривердиев, Н. Добронравов);

8. «Веселый марш монтажников» (из к/ф «Высота») (Р. Шедрин, В. Котов);

9. «Хорошие девчата» (из к/ф «Девчата») (А. Пахмутова, М. Матусовскиї);

10. «Беловежская пуща» (А. Пахмутова, Н. Добронравов);

11. «Разгово со счастьем» (из к/ф «Иван Васильевич меняет профессию») (А. Заџепин, ᄉ. Дербенев);

12. «Парень чернокожий» (ᄉ. Агутин);

13. «Темная ночь» (Н. Богословский, Н. Агатов);

14. «Я шагаю по Москве» (А. Петров, Г. Шпаликов);

15. «Т ридџать три коровы» (из к/ф «Мэри Поппинс, до свидания!») (М. Дунаевский, Н. Олев);

16. «Песенка Красной шапочки» (А. Рыбников, Ю. Михайлова);

17. «Есть только миг» (А. Заџепин, ᄉ. Дербенев);

18. «В землянке» (К. Листов, А. Сурков);

19. «Журавли» (Я. Френкель, Р. Гамзатов); 
20. «Дороги» (А. Новиков, Л. Ошанин);

21. «Смуглянка» (А. Новиков, Я. Шведов);

22. «C чего начинается Родина?» (В. Баснер, М. Матусовский);

23. «Позови меня с собой» (Т. Снежина);

24. «Этот мир» (А. Зајепин, Л. Дербенев);

25. «Студенческая дорожная» (Я. Френкель, М. Львовский);

26. «Yesterday» (из репертуара «The Beatles») ( $P$. McCartney, J. Lennon);

27. «The Power of love» (C. Derouge \& G. Mende, M.S. Applegate \& J. Rush).

Второй уровень:

1. «Боже, какой пустяк» (С. Трофимов);

2. «Веселый ветер» («Песня Роберта») (из к/Ф «Дети капитана Гранта») (И. Дунаевский, В. Лебедев-Кумач);

3. «Ветер перемен» (из к/Ф «Мэри Поппинс, до свидания!») (М. Дунаевский, Н. Олев);

4. «Волшебник-недоучка» (А. Заџепин, Л. Дербенев);

5. «У берез и сосен» (Ю. Антонов, И. Шаферан);

6. «Still loving you» (из репертуара группы «Scorpions») (R. Schenker);

7. «Куда уходит детство» (А. Заџепин, Л. Дербенев);

8. «Семь тысяч над землей» (В. Сюткин);

9. «Позвони мне, позвони» (из к/Ф «Карнавал») (М. Дунаевский, Р. РОждественский);
10. «My love is your love» (из репертуара W. Huston) (W. Jean \& J. Duplessis);

11. «Ишу тебя» (из к/Ф «31 июня») (А. Заџепин, Л. Дербенев);

12. «Моей душе покоя нет» (из к/Ф «Служебный роман») (А. Петров, С. Маршак);

13. «Осенний поџелуй» (А. Пугачева, И. Николаев);

14. «Три счастливых дня» (А. Пугачева, И. Резник);

15. «Песенка о хорошем настроении» (А. Лепин; В. Лившиџ, В. Коростылев);

16. «Для тебя» (из к/Ф «Когда наступает сентябрь») (Я. Френкель, И. Шаферан).

Третий уровень:

1. «Оранжевый галстук» (Е. Хавтан, В. Сюткин);

2. «Песня остается с человеком» (А. Островский, С. Островой);

3. «По волне моей памяти» (Д. Тухманов; Н. Гильен, перевод И. Тыняновой);

4. «Романс Дианы» (из к/ф «Собака на сене») (Г. Гладков, М. Донской);

5. «Ты говоришь мне о любви» (Э. Колмановский, Л. Дербенев);

6. «Душа» (Д. Маликов, И. Аветисьянџ);

7. «The music of the night» (из мюзикла «Призрак оперы» («The Phantom of the Opera»)) (A.Ll. Webber, Ch. Hart).

Приведем также несколько примеров заданий-тестов для проверки внутреннего слуха. Эти задания можно давать 
при подведении итогов работы в начальном периоде, завершая работу над песнями первого уровня сложности. Џель заданий - проверить точность слуховых представлений при определении мелодических структур (ладовых архетипов или структур, образованных по принџипу связи большего / меньшего ладоакустических полей [Подробнее см.: 1; 2]). Эти трихордные мотивы, мини-структуры сегментированы, сходны с лексемами и, так или иначе, выделяются в мелодиях песен. Трихорды различных видов очень часто встречаются в массовой песне. Воздействуя на сферу бессознательного и глубоко укорененные в памяти в качестве архетипов, они во многом способствуют популярности эстрадной музыки. Тем не менее, определение этих структур на слух и запись их нотами нередко вызывают трудности. Очень часто асимметричные трихорды студенты ошибочно записывают как движение по звукам мажорного или минорного трезвучий, в которых асимметрия также присутствует, но сглажена.

В задания включены мелодии песен, предварительно выученных наизусть с помощью сольфеджирования. Некоторые из них могут быть выучены не только как самодиктанты, но также по учебникам сольфеджио, по сборникам песен. Напомним, что задания выполняются в тишине и не предполагают пение вслух, игру на фортепиано, использование фортепианной клавиатуры в планшетах и других мобильных устройствах.

Задание 1. Отметьте знаком «+» песни, в которых есть нисходящий трихорд в квинте с последователь- ностью полей $\mathrm{M} \downarrow Б \downarrow$, где $\mathrm{M}$ - меньшее, а Б - большее ладоакустическое поле, или в интервальном измерении - $6.2 \downarrow .4 \downarrow$ ?

\begin{tabular}{|l|l|l|}
\hline 1. & Подмосковные вечера & \\
\hline 2. & Маленький принџ & \\
\hline 3. & Парень чернокожий & \\
\hline 4. & My favorite things & \\
\hline
\end{tabular}

Задание 2. Отметьте знаком «+» песни, в которых есть нисходящиий трихорд в квинте с последовательностью полей $\mathrm{L} \downarrow \mathrm{M} \downarrow($ ч. $4 \downarrow 6.2 \downarrow) ?$

\begin{tabular}{|l|l|l|}
\hline 1. & Улыбка & \\
\hline 2. & Подмосковные вечера & \\
\hline 3. & My favorite things & \\
\hline 4. & Тридџать три коровы & \\
\hline
\end{tabular}

Задание 3. Отметьте знаком «十» песни, в которых есть нисходящиий трихорд в кварте с последовательно-

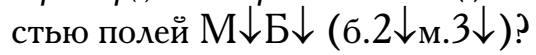

\begin{tabular}{|l|l|l|}
\hline 1. & Веселый марш монтажников & \\
\hline 2. & Девчата & \\
\hline 3. & Непогода & \\
\hline 4. & Парень чернокожий & \\
\hline 5. & Беловежская пуща & \\
\hline
\end{tabular}

Одно из заданий для проверки внутреннего слуха, вызывающее у студентов особый интерес, — это тест «Угадай мелодию», где нужно узнать мелодию по нотной записи ее небольшого фрагмента. Список песен, которые студенты должны знать, оговаривается заранее. Ниже приводится пример такого теста. 
Тональность определяется по ключевым знакам, настройка на тональность осушествляется внутренним слухом. Все эти «экстремальные условия» для полных энергии студентов-эстрадников создают игровую ситуаџию, в которой они могут испытать себя, проверить свои силы. «А можно я?», «А дайте мне!» - таковы возгласы самых нетерпеливых, «рвушихся в бой», сопровождающие это задание, и такое активно заинтересованное отношение студентов говорит само за себя.

Постоянный поиск новых методов развития слуха сушествовал всегда, и наше время не исключение. В настояшей ста- тъе мы хотели еше раз обратить внимание на необходимость развития способности к слуховым представлениям и умения свободно управлять ими, что в конечном итоге ведет к развитию музыкальнотворческих способностей. При нынешней весьма скромной обеспеченности учебниками сольфеджио, основанными на эстрадной музыке, развитие музыкального слуха посредством самодиктантов на материале эстрадной песни, музыки из кинофильмов и мюзиклов представляется не просто одним из возможных путей решения проблемы, но методом самостоятельной работы, соответствуюшим современной парадигме образования.

\section{Тест «Угадай мелодию»}
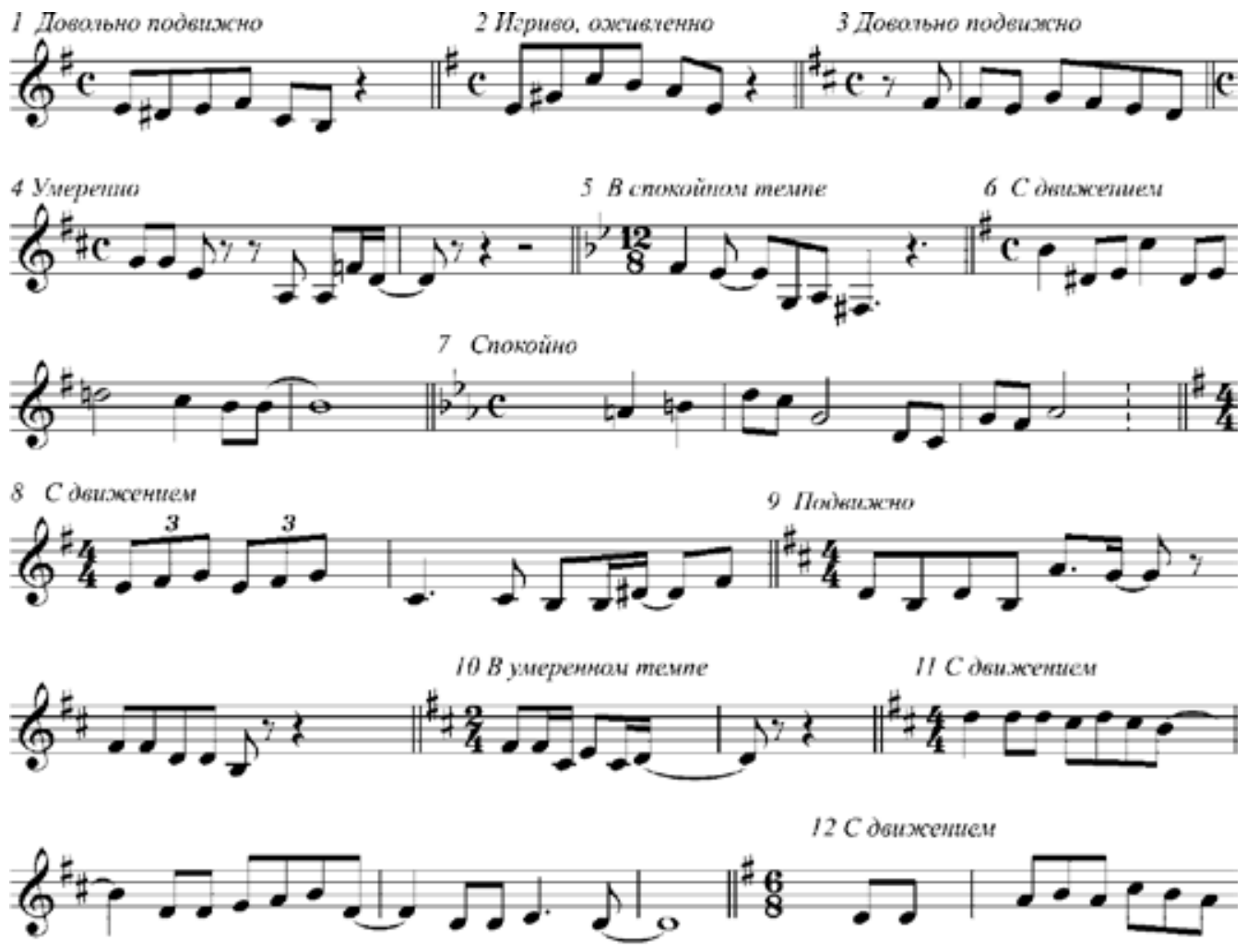
Елена Алкон
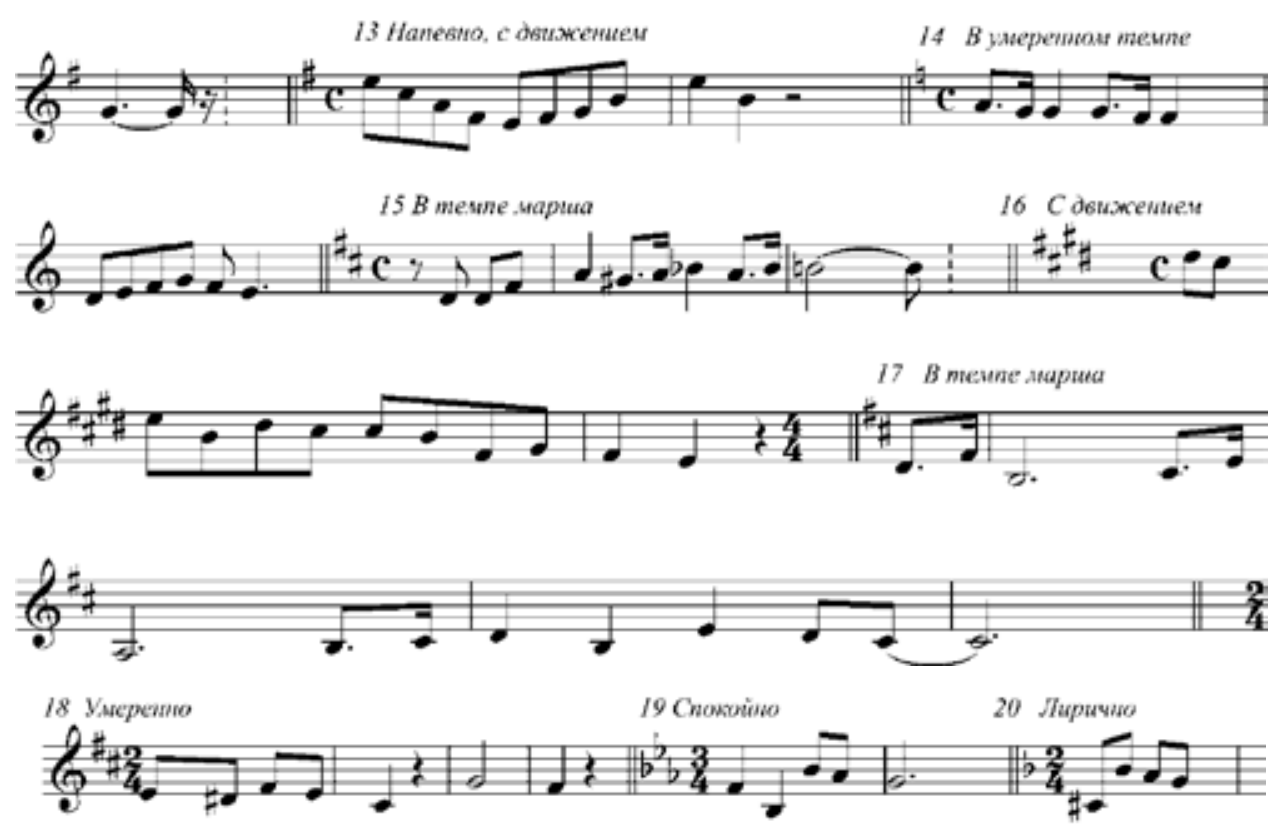

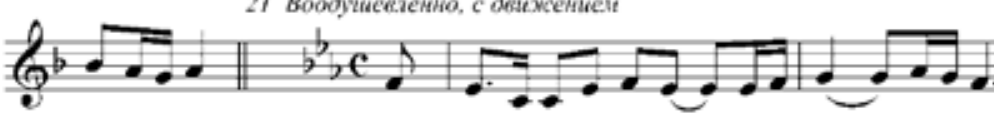

4

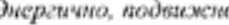
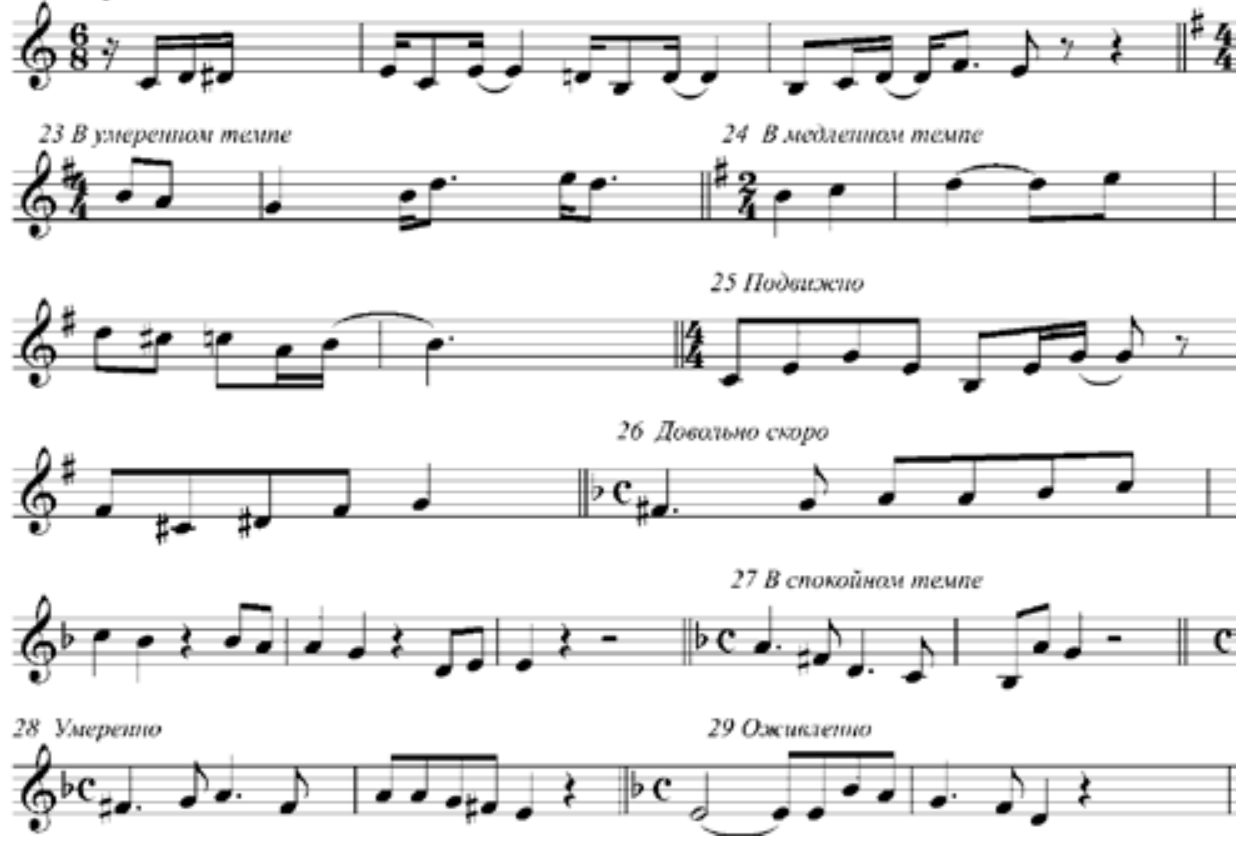

82 


\section{ЛИТЕРАТУРА}

1. Алкон Е.M. Методология анализа ладовых архетипов. Учебно-методическое пособие по курсу «Методология музыкознания». Владивосток: РИО ДВГАИ, 2008. 38 с.

2. Алкон E.M. Мелос, модальность и музыкальное мышление мифологического типа: к развитию идеи Э. Курта / / Ученые записки Российской академии музыки имени Гнесиных. 2014. № 1 (8). С. 13-23.

3. Берак O.Д. Проблемы развития личности в проџессе обучения сольфеджио, или Как не отвратить учеников от занятий музыкой // Музыкальное образование в контексте культуры: Вопросы теории, истории и методологии. Материалы Международной научной конференџии 21-23 октября 2008 года / М.: РАМ им. Гнесиных, 2009. С. 321-327.

4. Бычков Ю.Н. Основы формирования мелодического ладового слуха: Лекџия. М.: РАМ им. Гнесиных, 1993. 48 с.

5. Кирнарская Д.К. Психология спеџиальных способностей. Музыкальные способности. M.: Таланты - XXI, 2004. 496 с.

6. Ключко С.И. Традиџионная музыкальная письменность Китая // Музыковедение. 2008. № 5. С. $62-67$.

7. Ключко С.И. Традиџионная музыкальная письменность Китая и Кореи: учебное пособие. Владивосток: РИО ДВГАИ, 2014. 100 с.

8. Оськина С.Е. Внутренний музыкальный слух. М.: Музыка, 1977. 72 с.

9. Оськина С.Е., Парнес Д.Г. Музыкальный слух: Теория и методика развития и совершенствования. 2-е изд., испр. и доп. М.: ООО «Издательство АСТ», 2003.78 с.

10. Пигров К.К., Шип В.И. Сольфеджио для дирижерско-хоровых отделений музыкальных училищ. М.: Музыка, 1970. 504 с.

11. Теплов Б.М. Психология музыкальных способностей / Отв. ред. Э.А. Голубева, Е.П. Гусева, В.А. Кольџова, О.Е. Серова. М.: Наука, 2003. 379 с.

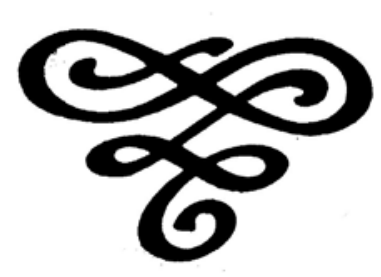

